\section{INEQUALITIES IN THE MOTION OF THE} MOON.'

THE most interesting result of Prof. Newcomb's researches on the planetary inequalities in the moon's motion is that he has found $\mathbf{I}^{\prime \prime} \cdot \mathrm{I} 4$ as the theoretical coefficient of the Jupiter evection term. This term was discovered empirically by Prof. Newcomb in 1876 , and Mr. Nevill assigned its origin to Jupiter. Dr. Hill and Radau independently computed its coefficient as $0^{\prime \prime} \cdot 9$. Two or three years ago it was pointed out that the observations indicated a coefficient $I^{\prime \prime} \cdot I$, and now Prof. Newcomb has obtained the same result by theory. This term is now worked out; the subject begins and ends with Prof. Newcomb, and has lasted thirty-one years. No indication is given in the memoir before us as to why Hill and Radau concurred in an imperfect value. It was a curious incident, as we know of no other case where any result of either of these two mathematicians has required revision.

In order to illustrate the methods of the memoir, we briefly indicate the process of calculating the Jupiter evection term.

First Stage.-Using the ordinary notation supplemented by $\alpha=\log a$, Prof. Newcomb starts from Delaunay, vol. ii., pp. $235^{-6}$ and 800 , and obtains on p. I9 the equations of variation

$$
\begin{aligned}
& \frac{d}{d(n t)} \alpha=\frac{a}{\mu}\left(\alpha_{1} \frac{\partial \mathrm{P}_{1}}{\partial l}+\alpha_{2} \frac{\partial \mathrm{P}_{1}}{\partial \pi}+a_{3} \frac{\partial \mathrm{P}_{1}}{\partial \theta}\right) \\
& -\frac{d}{d(n t)} e=\frac{a}{\mu}\left(e_{1} \frac{\partial \mathrm{P}_{1}}{\partial l}+e_{2} \frac{\partial \mathrm{P}_{1}}{\partial \pi}+e_{3} \frac{\partial \mathrm{P}_{1}}{\partial \theta}\right) \\
& \left.\frac{d}{d(n t)}\right)^{\prime} \gamma=\frac{a}{\mu}\left(\gamma_{1} \frac{\partial \mathrm{P}_{2}}{\partial l}+\gamma_{2} \frac{\partial \mathrm{P}_{1}}{\partial \pi}+\gamma_{3} \frac{\partial \mathrm{P}_{1}}{\partial \theta}\right) \\
& \frac{d}{d(n t)} l_{0}=-\frac{a}{\mu}\left(a_{1} \frac{\partial \mathrm{P}_{1}}{\partial \alpha}+e_{1} \frac{\partial \mathrm{P}_{1}}{\partial e}+\gamma_{1} \frac{\partial \mathrm{P}_{1}}{\partial \gamma}\right) \\
& \frac{d}{d n t)} \pi_{0}=-\frac{a}{\mu}\left(a_{2} \frac{\partial \mathrm{P}_{1}}{\partial \alpha}+e_{2} \frac{\partial \mathrm{P}_{1}}{\partial e}+\gamma_{2} \frac{\partial \mathrm{P}_{1}}{\partial \gamma}\right) \\
& \frac{d}{d(n t)} \theta_{0}=-\frac{a}{\mu}\left(a_{3} \frac{\partial \mathrm{P}_{1}}{\partial \alpha}+e_{3} \frac{\partial \mathrm{P}_{1}}{\partial e}+\gamma_{3} \frac{\partial \mathrm{P}_{1}}{\partial \gamma}\right)
\end{aligned}
$$

$P_{1}$ being the potential of the disturbing forces.

He also gives (p. I8) the numerical values of $\alpha_{1}$, \&c., as follows :-

$$
\begin{array}{lll}
\alpha_{1}=+2.0228 & e_{1}=0.0168 & \gamma_{1}=-0.0229 \\
\alpha_{2}=-0.0301 & e_{2}=-19.1534 \gamma_{2}=-0.0200 \\
\alpha_{3}=+00075 & e_{3}=+0.0026 & \gamma_{3}=-5.5700
\end{array}
$$

Second Stage.-Neglecting certain small terms, we have for the potential of the direct action of a planet

$$
\frac{a}{\mu} \mathrm{P}_{1}=\mathrm{MK}\left(\xi^{2}-\eta^{2}\right) \quad \frac{1}{2} \mathrm{MC}\left(\mu^{2}-3 \zeta^{2}\right)+\mathrm{MD} 2 \xi \eta,
$$

and a similar form for the potential of the indirect action

$$
\frac{a}{\mu} \mathrm{P}_{1}=-m^{2} \mathrm{G}\left(\xi^{2}-\eta^{2}\right)-m^{2} J\left(\rho^{2}-3 \zeta^{2}\right)+m^{2} \mathrm{I} 2 \xi \eta \text {. }
$$

For brevity, the sum of the two may be written

$$
\frac{a}{\mu} \mathrm{P}_{1}=10^{-3} \mathrm{~K}^{\prime}\left(\xi^{2}-\eta^{2}\right)-10^{-3} \mathrm{C}^{\prime}\left(\rho^{2}-3 \zeta^{2}\right)+10^{-3} \mathrm{D}^{\prime} 2 \xi \eta \text {. }
$$

In the above formulæ, $\xi \quad \eta, \quad \zeta$, denote the lunar coordinates divided by the moon's mean distance, the axis of $\xi$ being directed towards the mean sun;

$$
\rho^{2}=\xi^{2}+\eta^{2}+\zeta^{2}
$$

and the coefficients $\mathrm{MK}, \mathrm{MC}, \mathrm{MD}, m^{2} \mathrm{G}, m^{2} \mathrm{~J}, m^{2} \mathrm{I}$ are known functions of the positions of the earth and the disturbing planet in their orbits. Of these six coefficients, the expansion of the first three in the form

$$
\Sigma \sin ^{\cos } i\left(g_{4}-g^{\prime}\right)+i g^{\prime},
$$

$i, j$ being integers, is exceedingly troublesome, and the expansion of the other three assumes that the mutual perturbations of the earth and planet have been calculated.

We are going to illustrate the methods of the memoir by considering as an example the perturbations arising from terms in $P_{1}$ with argument

$$
2 \pi-2 \mathrm{~J} \text { or } 2 \mathrm{D}-2 \mathrm{~g}+2 g^{\prime}-2 \mathrm{~J} \text {. }
$$

I "Investigation of Inequalities in the Motion of the Moon produced by the Action of the Planets." By Simon Newcomb, assisted by Frank E. Ross. Pp. viii +160 . (Washington: The Carnegie Institution, I907). NO. 1985 , VOL. 77$]$
Such a term may arise in $\mathrm{P}_{1}$ by combining a lunar argument $2 \mathrm{D}-2 g+j g^{\prime}$ with a planetary argument

$$
-j g^{\prime}+2 g^{\prime}-2 J \text {, }
$$

$j$ being given any integral value; but we will confine ous attention to the case $j=0$, which gives rise to the only sensible term of the whole number.

We require, therefore, to pick out the planetary terms with argument $2 \mathrm{~J}-2 g^{\prime}=\mathrm{N}_{4}$, and the lunar terms with argument $2 \mathrm{D}-2 g=\mathrm{N}$.

The following extracts from the memoir cover the first part of the work:-

From p. 85, Table XXII. :-

$10^{3} \mathrm{MK}=+6^{\prime \prime} \cdot 119 \cos \mathrm{N}_{4}+0^{\prime \prime} \cdot 006 \sin \mathbf{N}_{4}$ $\frac{1}{2} 10^{3} \mathrm{MC}=-0^{\prime \prime} \cdot 293 \cos \mathrm{N}_{4}+\mathrm{O}^{\prime \prime} \cdot \mathrm{OOI} \sin \mathrm{N}_{4}$ $10^{3} \mathrm{MD}=-\mathrm{O}^{\prime \prime} \cdot 005 \cos \mathrm{N}_{4}+6^{\prime \prime} \cdot$ I I $_{4} \sin \mathrm{N}_{4}$

From p. 97, Table XXXIII. :$10^{3} m^{2} \mathrm{G}=-24^{\circ} 668 \cos \mathrm{N}_{4}-0^{\prime \prime} .35^{8} \sin \mathrm{N}_{4}$ $10^{3} m^{2} \mathrm{~J}=-3.096 \cos \mathrm{N}_{4}-\mathrm{o}^{\prime \prime} \cdot 06 \mathrm{I} \sin \mathrm{N}_{4}$ $I^{3} m^{2} \mathbf{I}=+0 \cdot 363 \cos \mathbf{N}_{4}-23^{\prime \prime} \cdot 488 \sin \mathbf{N}_{4}$

Hence by addition, p. I 45 , Table XLV.,

$$
\begin{aligned}
& \mathrm{K}^{\prime}=+30^{\prime \prime} \cdot 8 \mathrm{I} \cos \mathrm{N}_{4}+\left(0^{\prime \prime} \cdot 38 \sin \mathrm{N}_{4}\right) \\
& \mathrm{C}^{\prime}=-8^{\prime \prime} \cdot 39 \cos \mathrm{N}_{4}-\left(\mathrm{o}^{\prime \prime} \cdot 06 \sin \mathrm{N}_{4}\right) \\
& \mathrm{D}^{\prime}=\left(+\mathrm{O}^{\prime \prime} \cdot 35 \cos \mathrm{N}_{4}\right)-\mathrm{I}^{\prime \prime} \cdot 37 \sin \mathrm{N}_{4}
\end{aligned}
$$

It will soon appear that the six terms of $\mathrm{K}^{\prime}, \mathrm{C}^{\prime}, \mathrm{D}^{\prime}$ fall into two groups of three; one group of three is indicated by brackets, and will not be proceeded with, as the other and more important group suffices for illustration.

Third Stage.-With the notation (see p. 24)

$$
\begin{array}{r}
\xi^{2}-\eta^{2}=2 p \cos \mathrm{N} \\
\rho^{2}-3 \boldsymbol{S}^{2}=2 q \cos \mathrm{N} \\
2 \xi \eta=k \sin \mathrm{N}
\end{array}
$$

we extract from Table XL., p. II2, for this argument $\mathrm{N}=-2 g+2 \lambda-2 \lambda^{\prime}=2 \mathrm{D}-2 g=2 \pi-2 g^{\prime}$, the values

$$
\begin{array}{lll}
2 p=+0.007809 & 2 \frac{\partial p}{\partial \alpha}=+0.00030 & 2 \frac{\partial p}{\partial e}=+0.28409 \\
2 q=+0.001807 & 2 \frac{\partial q}{\partial \alpha}=+0.00373 & 2 \frac{\partial q}{\partial e}=+0.06569 \\
k=+0.007 \text { 185 } & \frac{\partial k}{\partial \alpha}=-0.00060 & \frac{\partial k}{\partial e}=+0.26169
\end{array}
$$

and we note that the differentials with regard to $\gamma$ are insensible.

These expansions are derived partly from Delaunay's lunar theory and partly from Brown's.

Fourth Stage.-In the differential equations of variation put $\frac{a}{\mu} \mathrm{P}_{1}=2 p \cos \mathrm{N}$.

$$
\frac{d}{d(n t)} a=-2 p \sin \mathrm{N} . \alpha_{0} \text { where } \alpha_{0}=\imath \alpha_{1}+\iota^{\prime} \alpha_{2}+\iota^{\prime \prime} \alpha_{3}
$$

( $\iota \iota^{\prime}, \iota^{\prime \prime}$, are the coefficients of $l, \pi, \theta$ in $\mathrm{N}$, or $2 \pi-2 g^{\prime}$, so that $\imath^{\prime}=2, \imath=\iota^{\prime \prime}=0$ ).

Similarly,

$$
\frac{d}{d(n t)} e=-2 p \sin \text { N. } e_{0} \text { where } e_{0}=t e_{1}+\iota^{\prime} e_{2}+\iota^{\prime \prime} e_{3} \text {. }
$$

We shall drop the equation for $\gamma$, and extract from: Table XLVII., p. 146 , the values

$$
\alpha_{0}=-0.0602 \quad i_{0}=-38 \cdot 307,
$$

as may be easily verified from the values of $2 a_{2}$ and $2 e_{2}$ at the beginning of this article.

From Table XLVIII., p. I47, we extract values of products of $p q \frac{1}{2} k$ by $a_{0}$ and $e_{0}$ :-

$\alpha_{0} p=-0.000 \quad 235 \quad \alpha_{0} q=-0^{\circ} 000 \quad 054 \quad \frac{1}{2} \alpha_{0} k=-0.000 \quad 216$ $e_{0} p=-0.14920 \quad e_{0} q=-0.03428 \quad \frac{1}{2} e_{0} k=-0.13790$

Again, noting that

$$
\frac{a}{\mu} \frac{\partial \mathrm{P}_{1}}{\partial \alpha}=\left(2+\frac{\partial}{\partial \alpha}\right)\left(\stackrel{\alpha}{\mu} \mathrm{P}_{1}\right)
$$

$-\frac{d}{d(n t)} l_{0}=\left\{a_{1}\left(4 p+2 \frac{\partial p}{\partial a}\right)+e_{1} 2 \frac{\partial p}{\partial e}+\gamma_{1} 2 \frac{\partial p}{\partial \gamma}\right\} \cos \mathbf{N}=2 L^{\prime} \cos \mathbf{N}$ $-\frac{a}{d(n t)} \pi_{0}=\left\{a_{2}\left(4 p+2 \frac{\partial p}{\partial a}\right)+e_{2}^{\prime} 2 \frac{\partial p}{\partial e}+\gamma_{2} 2 \frac{\partial p}{\partial \gamma}\right\} \cos \mathrm{N}=2 \mathrm{P}^{\prime} \cos \mathrm{N}$, we shall drop the equation for $\theta_{0}$, and noting that when $q$ and $k$ respectively replace $p$, then $L^{\prime}, \mathrm{P}^{\prime}$ become in Prof. Newcomb's notation $L^{\prime \prime}, \mathrm{P}^{\prime \prime}$ and $\mathrm{L}_{4}, \mathrm{P}_{4}$. 
From Table XLIX., p. $14 \%$, we extract :-

$$
\begin{aligned}
& L^{\prime}=+0.013 \quad 67 \quad 2 e \mathrm{P}^{\prime}=-0.29875 \\
& \mathrm{~L}^{\prime \prime}=+0.00684 \quad 2 e \mathrm{P}^{\prime \prime}=-0.069 \text { o8 } \\
& L_{4}=+0.0235^{1} \quad e P_{4}=-0.275 \quad 19
\end{aligned}
$$

In Prof. Newcomb's value of $\mathrm{L}$ we think a small error (about 0.00020 ) has been introduced.

Now putting

$$
\begin{aligned}
\frac{a}{\mu} \mathrm{P}_{1} & =\mathrm{K}_{c}^{\prime} \cos \mathrm{N}_{4} 2 p \cos \mathrm{N} \\
& -\mathrm{C}_{c}^{\prime} \cos \mathrm{N}_{4} 2 q \cos \mathrm{N} \\
& +\mathrm{D}_{s}^{\prime} \sin \mathrm{N}_{4} k \sin \mathrm{N}
\end{aligned}
$$

we get

$$
\begin{aligned}
& -\frac{d}{d(n i t)} l_{0}=\left(2 \mathrm{~K}_{c}{ }^{\prime} \mathrm{L}^{\prime}-2 \mathrm{C}_{c}{ }^{\prime} \mathrm{L}^{\prime \prime}=2 \lambda_{\mathrm{T}}\right) \quad \cos \mathrm{N}_{4} \cos \mathrm{N} \\
& +\mathrm{D}_{8}{ }^{\prime} \mathrm{L}_{4} \quad \sin \mathrm{N}_{4} \sin \mathrm{N} \\
& -\frac{d^{\prime}}{d(n t)} \pi_{0}=\left(2 \mathrm{~K}_{c}{ }^{\prime} \mathrm{P}^{\prime}-2 \mathrm{C}_{c}{ }^{\prime} \mathrm{P}^{\prime \prime}=\frac{2 \pi_{\mathrm{I}}}{e}\right) \cos \mathrm{N}_{4} \cos \mathrm{N} \\
& +\mathrm{D}_{8}{ }^{\prime} \mathrm{P}_{4} \quad \sin \mathrm{N}_{4} \sin \mathrm{N} \\
& \frac{d}{d(\text { int })} \alpha=\left(-2 \mathrm{~K}_{c}^{\prime} \alpha_{0} \not+2 \mathrm{C}_{c}^{\prime} \alpha_{0} g=2 a_{2}\right) \cos \mathrm{N}_{4} \cdot \sin \mathrm{N}
\end{aligned}
$$

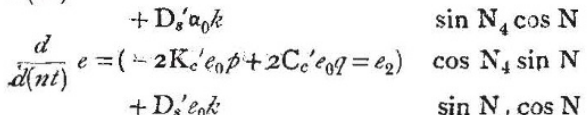

At this point we shall reject the terms in $\mathrm{N}+\mathrm{N}_{4}$ and write

$$
\begin{gathered}
-\frac{d}{d(n t)} l_{0}=\left(\lambda_{1}+\frac{1}{\lambda_{2}} \mathrm{D}_{s}^{\prime} \mathrm{L}_{4}=h_{i, c^{\prime}}\right) \cos \left(\mathrm{N}-\mathrm{N}_{4}\right) \\
-e \frac{d}{d(n t)} \pi_{o}=\left(\pi_{1}+\frac{1}{2} \mathrm{D}_{s}^{\prime} e \mathrm{P}_{4}=e h_{\pi, c^{\prime}}\right) \cos \left(\mathrm{N}-\mathrm{N}_{4}\right) \\
\frac{d}{d(n t)} \alpha=\left(a_{2}-\frac{1}{2} \mathrm{D}_{s^{\prime}}^{\prime} \alpha_{0} k=h_{a, s^{\prime}}\right) \sin \left(\mathrm{N}-\mathrm{N}_{4}\right) \\
\frac{d}{d(n t)} e=\left(\frac{1}{2} e_{2}-\frac{1}{2} \mathrm{D}_{s}^{\prime} e_{0} k=h_{e}, s^{\prime}\right) \sin \left(\mathrm{N}-\mathrm{N}_{4}\right) . \\
\text { Putting } \nu^{\prime}=\frac{\text { mean motion of moon }}{\text { mean motion of } \mathrm{N}-\mathrm{N}_{4}}
\end{gathered}
$$

we obtain on integration

$$
\begin{gathered}
2 \Delta e=-2 \nu^{\prime} h_{e, g^{\prime}} \cos \left(\mathrm{N}-\mathrm{N}_{4}\right)=2 e_{e}^{\prime} \cos \left(\mathrm{N}-\mathrm{N}_{4}\right) \\
2 e \Delta \pi=-\nu^{\prime} 2 e h_{\pi, c^{\prime}} \sin \left(\mathrm{N}-\mathrm{N}_{4}\right)=2 e \pi_{8}^{\prime} \cdot \sin \left(\mathrm{N}-\mathrm{N}_{4}\right),
\end{gathered}
$$

and by a double integration, remembering that $\Delta x=-\frac{2}{3} \frac{\Delta n}{n}$,

$$
\Delta l=\nu^{\prime}\left(\frac{3}{2} \nu^{\prime} h_{a, s}-h_{l},,_{1}\right) \sin \left(\mathbf{N}-\mathbf{N}_{4}\right)=l_{s^{\prime}}^{\prime} \sin \left(\mathbf{N}-\mathbf{N}_{4}\right) .
$$

From p. 153 we extract

$$
\begin{aligned}
& \nu^{\prime}=232 \cdot 720 \quad l_{s}^{\prime}=+0^{\prime \prime} \cdot 256 \\
& 2 e_{c}^{\prime}=-\mathrm{I}^{\prime \prime} \cdot 158 \\
& 2 e \pi_{s}^{\prime}=+x^{\prime \prime} \cdot 164 .
\end{aligned}
$$

Lastly, if we substitute in

$$
\text { we get } \begin{aligned}
\delta v=\delta l+2 \delta e \sin g+2 \cos g(e \delta l-e \delta \pi) \\
\delta v=-\mathrm{I}^{\prime \prime} . \mathrm{I} 5 \sin (g+2 \pi-\mathrm{J}) .
\end{aligned}
$$

Turning now to the statement of final results on pp. $\mathbf{r}^{6-9}$, we note, with the single exception of the Jupiter evection term, its mainly negative character. Results previously given by Radau and Brown are only very slightly modified, generally by quantities quite insensible to observation. Moreover, no explanation has been reached of the unknown term of long period. Thirty years ago Prof. Newcomb, in what are known as Newcomb's corrections, assigned a coefficient $15^{\prime \prime} \cdot 5$ and a period of 273 years with an argument arising from the action of Venus to this unknown term. It is now known that the argument is impossible. The present writer thinks that both the coefficient and the period require some increase. At any rate, Newcomb's empirical term has now ceased to represent the observed motion of the moon. It is not, of course, to be expected that empiricism will predict with any accuracy for any length of time. In the last paragraph of his memoir, Prof. Newcomb recalls his attempt to establish an inequality in the earth's rotation that should simultaneously account for the motion of the moon and the transits of Mercury. About forty years ago there was an impression that planetary astronomy had been worked out by Hansen and Le Verrier. The lumar tables of the one and the planetary tables of the other marked immense advances on those of their predecessors, and the extant observations were not sufficient to sound any note of warning except that it might have been noted that Hansen's tables did not account for the ancient eclipses. We now have new planetary tables and the materials for new tables of the moon, but we cannot share the satisfaction of our predecessors of forty years ago. A very considerable list of residual phenomena has accumulated. Apses and nodes and secular terms do not accord with theory. In the moon some periodic terms are unexplained. In Mars it seems as it a term with one second as coefficient and period about twenty years is required to reconcile theory and observation. In the present memoir Prof. Newcomb has presímably excluded the action of the planets as a possible explanation of the vagaries of the moon.

A word ought to be said as to the excellent form of presentation of the subject by Prof. Newcomb. It illustrates the Roman maxim, so often quoted by the late headmaster of Eton, "Divide et impera" "-subdivide into sections, and you will get the grip of it.

\section{NEW FACTS ABOUT THE ARUNTA.}

THE Arunta of Central Australia have loomed large of late in ethnological controversy, but we are destined to hear further discussion in the near future. Hitherto our information has been derived first from the observations of Mr. F. J. Gillen in part iv. of "The Report of the Horn Expedition to Central Australia," 1896 , and later from the two well-known admirable books by Prof. Baldwin Spencer and Mr. Gillen. In a recent number of Globus (Bd. xci., No. I8, p. 285) Herr M. Freiher v Leonhardi has an article "On some Religious and Totemic Conceptions of the Aranda and Loritja in Central Australia," based upon information received from Herr C. Strehlow and Herr Reuther, of the Neuen Dettelsaur Mission, who have a mastery over the language of the Arunta, or Aranda. Some of the information thus obtained is so different from that recorded by Spencer and Gillen that it opens a new phase in the discussions concerning these remarkable people. Only the more salient points of Leonhardi's article can be here given; students will have to study it in detail, and they will await with eagerness the promised volume.

The Arunta certainly believe in a supreme, good, heavengod called Altjira; he is the god of the upper world, and has little to do with men. He has the appearance of a tall man with a red skin and long hair falling over his shoulders, but he has feet like an emu, he eats vegetable food, and the flesh of the emu, which he spears. $\mathrm{He}$ is surrounded by beautiful youths and maidens, who are immortal. The stars are his camp-fires, the Milky Way his hunting-ground. Only certain specially conspicuous stars, such as the evening star, the Pleiades, \&c., and sun and moon are ancestors of the Arunta, who once lived on earth and had certain totems. From this Altjira, who lives in heaven, and of whom no Tjurunga (Churinga) exists, must be elearly distinguished the ancestors, honoured as gods and endowed with superhuman powers, who lived on earth sometimes as animals, sometimes as men. In three neighbouring groups the supreme God is distinguished from the totem gods in the following wav :-Dieri, supreme being, Mura, deified ancestors or totem gods, Mura-Mura; Arunta, supreme being, Altjira (the Uncreated), totem gods, Altjira-ngamitjina (the everlasting Uncreated) or Intrapa (the Undying); Loritcha, supreme being, Tukura (the Uncreated), totem gods, Tukutita (the efernal Uncreated). Originally Gillen described a great spirit (Ulthaana), of whom no mention was made in the subsequent works, but in these "the most important spirit individual in the Arunta tribe is Twanyirika," though we are told he is not regarded " as a supreme being who in any way whatever was supposed to inculcate moral idcas." Ncither is Altjira the guardian of cults and morals. 